\title{
Article
}

Doi 10.5943/mycosphere/7/2/11

Copyright $($ ) Guizhou Academy of Agricultural Sciences

\section{Selection of a highly productive strain of Pholiota adiposa}

\author{
Rong $\mathrm{CB}^{1}$, Song $\mathrm{S}^{1}$, Niu $\mathrm{YR}^{1}$, Xu $\mathrm{F}^{1}$, Liu $\mathrm{Y}^{1,2}$, Zhao $\mathrm{S}^{1}$, Wang $S X^{1,2}$ \\ ${ }^{1}$ Institute of Plant and Environment Protection, Beijing Academy of Agriculture and Forestry Sciences, Beijing \\ Engineering Research Center for Edible Mushroom, Beijing 100097, China; \\ ${ }^{2}$ Key Laboratory of Urban Agriculture (North), Ministry of Agriculture, Beijing 100097, China.
}

Rong CB, Song S, Niu YR, Xu F, Liu Y, Zhao S, Wang SX 2016 - Selection of a highly productive strain of Pholiota adiposa. Mycosphere 7(2), 226-235, Doi 10.5943/mycosphere/7/2/11

\begin{abstract}
Comparative studies on mushroom strains from various localities are one of the best ways to screen for strains with improved yield and quality. The current study was conducted to evaluate the mycelial growth rate, primordial initiation time, biological efficiency, and nutritional components of four domesticated and one cultivar (Control) strain of Pholiota adiposa. Strain JZB2116005 exhibited the highest mycelial growth rate $(2.56 \pm 0.03 \mathrm{~mm} / \mathrm{d})$, whereas the control strain JZB2116001 was lowest $(2.34 \pm 0.01 \mathrm{~mm} / \mathrm{d})$. The mycelial colonization time and primordial initiation time of different strains were not consistent with the mycelial growth rates. It took approximately 8-9 days and 11-12 days longer for control strain JZB2116001 to colonize the whole bags and to form primordial, than strain JZB2116005. The highest biological efficiency $(67.88 \pm 1.33 \%)$ was observed in strain JZB2116005 while the control strain JZB2116001 was worst $(41.35 \pm 1.72 \%)$. Fruiting bodies of strain JZB2116005 showed better morphological traits and higher chemical contents as compared with the control strain JZB2116001. Therefore, from a commercial point of view, it was necessary to replace strain JZB2116001 with strain JZB2116005 in production.
\end{abstract}

Key words - biological efficiency - cultivation - nutritional components - yield

\section{Introduction}

Pholiota adiposa (Fr.) Quel., an edible and medicinal mushroom, is widely distributed on the dead timber piles of poplars, willows, or birches in forest areas in China (Hu et al. 2012). The fruiting body of this mushroom is rich in proteins, essential amino acids, dietary fiber, trace elements, vitamins, and carbohydrates (Hui et al. 2003). Compounds extracted from the fruiting bodies of $P$. adiposa display a variety of important biological activities, such as antitumor (Jiang et al. 2007, Zhang et al. 2009, Hu et al. 2012), antimicrobial (Dulger 2004), anti-HIV-1 (Zhang et al. 2009, Wang et al. 2014a) and antioxidative activities (Ji et al. 2007, Deng et al. 2011, Wang et al. 2014a). Owing to the important nutritional and medicinal properties, cultivation of $P$. adiposa is prevalent worldwide, not only in China but also in several regions of Asia, Europe, and North America (Shimizu et al. 2003).

Recently, numerous reports regarding the comparative cultivation studies of Hericium species (Ko et al. 2005), Flammulina velutipes (Wang \& Wen 2014, Zhang et al. 2015), Pleurotus spp. (Zhang et al. 2012, Wang et al. 2014b), Pleurotus eryngii (Wu et al. 2011), Pleurotus ostreatus (Salmones et al. 2005), and Tremella fuciformis (Deng et al. 2014) have been published. However, 
the cultivation history of $P$. adiposa is poorly studied, hence, only a few papers are available on the cultural characteristics of $P$. adiposa (Morimoto et al. 1979, Meng et al. 2006, Shen et al. 2009, Li \& Qi 2010, Li et al. 2015). There are no comparative studies of different $P$. adiposa strains.

Therefore, the present study was initiated to compare the $P$. adiposa industrial cultivar with 4 new domesticated strains. These strains were evaluated in our preliminary estimation from 12 wild $P$. adiposa strains. Mycelial growth rate (MGR), primordial initiation time (PIT), biological efficiency (BE), and nutritional value of the fruiting bodies were tested to screen an efficient strain with good cultivation traits and nutritional components.

\section{Materials \& Methods}

\section{Microorganism and spawn preparation}

Twelve $P$. adiposa fruiting bodies collected from different places in Beijing, China, were isolated by tissue culture. The MGR, PIT, and BE were screened in our preliminary estimation. Eight strains were discarded for easily being contaminated by mold or unformed fruiting bodies in cultivation and four strains with relatively good cultivation traits were selected for further study (unpublished data). One cultivar (JZB2116001) with poorly cultivation traits was used as control in this study (Table 1). All the tested strains were deposited in the Beijing Engineering Research Center for Edible Mushroom, Beijing Academy of Agriculture and Forestry Sciences (BAAFS), Beijing, China.

Cultures were maintained on a potato dextrose agar (PDA, $200 \mathrm{~g} / \mathrm{l}$ of diced potatoes; $20 \mathrm{~g} / \mathrm{l}$ of glucose; $15 \mathrm{~g} / \mathrm{l}$ of agar) medium at $25{ }^{\circ} \mathrm{C}$. The spawn preparation was conducted according to the method described by Pant et al. (2006).

\section{Substrate preparation, inoculation, and incubation}

The cottonseed hulls, sawdust (Malus sylvestris), and wheat bran used in this study for cultivation of P. adiposa, were obtained from Beijing Yingliang Agricultural Development Co., Ltd (Beijing, China) and sun-dried. Substrates were prepared with $65 \%(\mathrm{w} / \mathrm{w})$ water content containing $60 \%$ cottonseed hull, $18 \%$ sawdust, $15 \%$ wheat bran, $5 \%$ corn flour, $1 \%$ gypsum, and $1 \%$ lime and placed in polypropylene bags $(17 \mathrm{~cm} \times 33 \mathrm{~cm} \times 0.04 \mathrm{~cm})$ at a packing density of $1,000 \mathrm{~g}$ of substrate per bag. A specially designed plastic ring was wrapped at the top end of the bag to form an opening, and an oblong conical plastic rod with a short rope was used to fill the bag from the opening. Then the top plastic ring was covered with a vent cap with microbiological filters. The bags were autoclaved at $121{ }^{\circ} \mathrm{C}$ for $120 \mathrm{~min}$. After sterilization, the plastic ring was open carefully and the oblong conical plastic rod was pulled out, a hole was left in the bag, and the spawns were inoculated into the hole at an amount of $2 \%(\mathrm{w} / \mathrm{w})$ of substrate fresh weight. Two-hundred-fifty replicated polypropylene bags were used and were divided into five replicates for each treatment.

Same substrates were placed in racing tubes for MGR measurements following the method described by Gregori et al. (2008), with a modification of the tube size (30-mm diameter, $260 \mathrm{~mm}$ length). Eighty grams of substrate per racing tube were used and sealed with cotton plugs on both sides of the tube. Racing tubes were autoclaved at $121{ }^{\circ} \mathrm{C}$ for $120 \mathrm{~min}$. Sterilized tubes were inoculated on one side by spreading the spawn on the substrates at an amount of $2 \%(\mathrm{w} / \mathrm{w})$ of substrate fresh weight. Five replicates were prepared for each strain.

The inoculated bags and tubes were kept in the spawn running room at $23-25{ }^{\circ} \mathrm{C}$ and 50 $60 \%$ relative humidity $(\mathrm{RH})$ under dark conditions. MGR on substrates filled in racing tubes was measured by the height $(\mathrm{mm})$ of the mycelia in the colonized substrates divided by the incubation time (days). Mycelial colonization time (MCT) (number of days from inoculation to complete colonization of the substrate by the mycelium in the culture bag) and PIT (number of days from inoculation to pinhead fruiting bodies) were recorded. 
Table 1 Sample data of the tested Pholiota adiposa strains.

\begin{tabular}{cccc}
\hline Strain No. & Origin & Host & $\begin{array}{c}\text { Acquisition } \\
\text { time }\end{array}$ \\
\hline JZB2116001 & Beijing Academy of Agriculture and Forestry Sciences & - & - \\
JZB2116003 & Lingshan, Mentougou district, Beijing, China & Willow & 2009.07 .20 \\
JZB2116004 & Lingshan, Mentougou district, Beijing, China & Willow & 2009.07 .15 \\
JZB2116005 & Zizhuyuan park, Haidian district, Beijing, China & Willow & 2009.09 .12 \\
JZB2116007 & Beijing Vegetable Research Center, BAAFS, Beijing, China & Willow & 2010.10 .09 \\
\hline
\end{tabular}

\section{Cropping, harvest, and determination of $\mathrm{BE}$}

After a complete spawn run, the bags were transferred to a refrigerated house to induce an occurrence of primordia and were cultured for $3-5 \mathrm{~d}$ at $0-5{ }^{\circ} \mathrm{C}$. Then, the bags were moved to a fruiting chamber that was maintained at $18 \pm 2{ }^{\circ} \mathrm{C}$ and $80-90 \% \mathrm{RH}$ with $12 \mathrm{~h}$ of illumination (300600 Lux). Bags were unfolded at the upper parts for cropping. To maintain the desired humidity, the chamber was sprayed intermittently during the growing time.

Fruiting bodies in two flushes were harvested before the caps started to open. The morphological traits of the fruiting bodies, including the pileus diameter and thickness, stipe length and diameter, were measured by digital calipers (Mitutoyo, Japan). The harvested fruiting bodies in each bag were weighed. At the end of the harvesting period, the accumulated data were used to calculate the BE (Yang et al. 2013).

$\mathrm{BE}(\%)=$ Weight of fresh mushrooms harvested per bag/weight of dry weight per bag $\times 100$

\section{Chemical analysis and statistical analysis}

Fruiting bodies of $P$. adiposa were collected randomly from the five tested strains in equal proportions after the first flush. Then they were dried in an oven at $60{ }^{\circ} \mathrm{C}$ to a constant weight and kept at $4{ }^{\circ} \mathrm{C}$. The chemical compositions, including moisture, dietary fiber, protein, energy, fat, ash, carbohydrate, and amino acids, of the samples were analyzed following the methods of Wang et al. (2015). All of the above analyses were performed by the PONY Testing International Group (Beijing, China).

Statistical analyses were conducted using the evaluation version of SPSS 20.0 for Windows. Data were obtained from two consecutive harvests, and chemical analyses were subjected to one-way analysis of variance. Differences among the means of eight treatments were assessed using Duncan's multiple range tests at the 95\% confidence level.

\section{Results}

\section{Mycelial growth and primordial initiation of different strains}

All the tested strains colonized on the substrates containing $60 \%$ cottonseed hull, $18 \%$ sawdust, $15 \%$ wheat bran, $5 \%$ corn flour, $1 \%$ gypsum, and $1 \%$ lime. Out of the tested strains, the highest MGR was observed for strain JZB2116005, followed by strain JZB216004; the control strain JZB2116001 showed the lowest MGR. The values of the MGR of the above three strains were $2.56 \pm 0.03 \mathrm{~mm} / \mathrm{d}, 2.45 \pm 0.03 \mathrm{~mm} / \mathrm{d}$, and $2.34 \pm 0.01 \mathrm{~mm} / \mathrm{d}$, respectively. There was a significant difference between strain JZB2116005 and the others with regard to the MGR; no difference was observed among strains JZB2116001, JZB2116003, and JZB2116007 (Figure 1 A). Correspondingly, the MCT and PIT of different strains were inconsistent with the MGR. It took approximately 8-9 d and 11-12 d longer for the control strain JZB2116001 to colonize whole bags and form primordia than strain JZB2116005, respectively (Figure $1 \mathrm{~B}, \mathrm{C}$ ). 

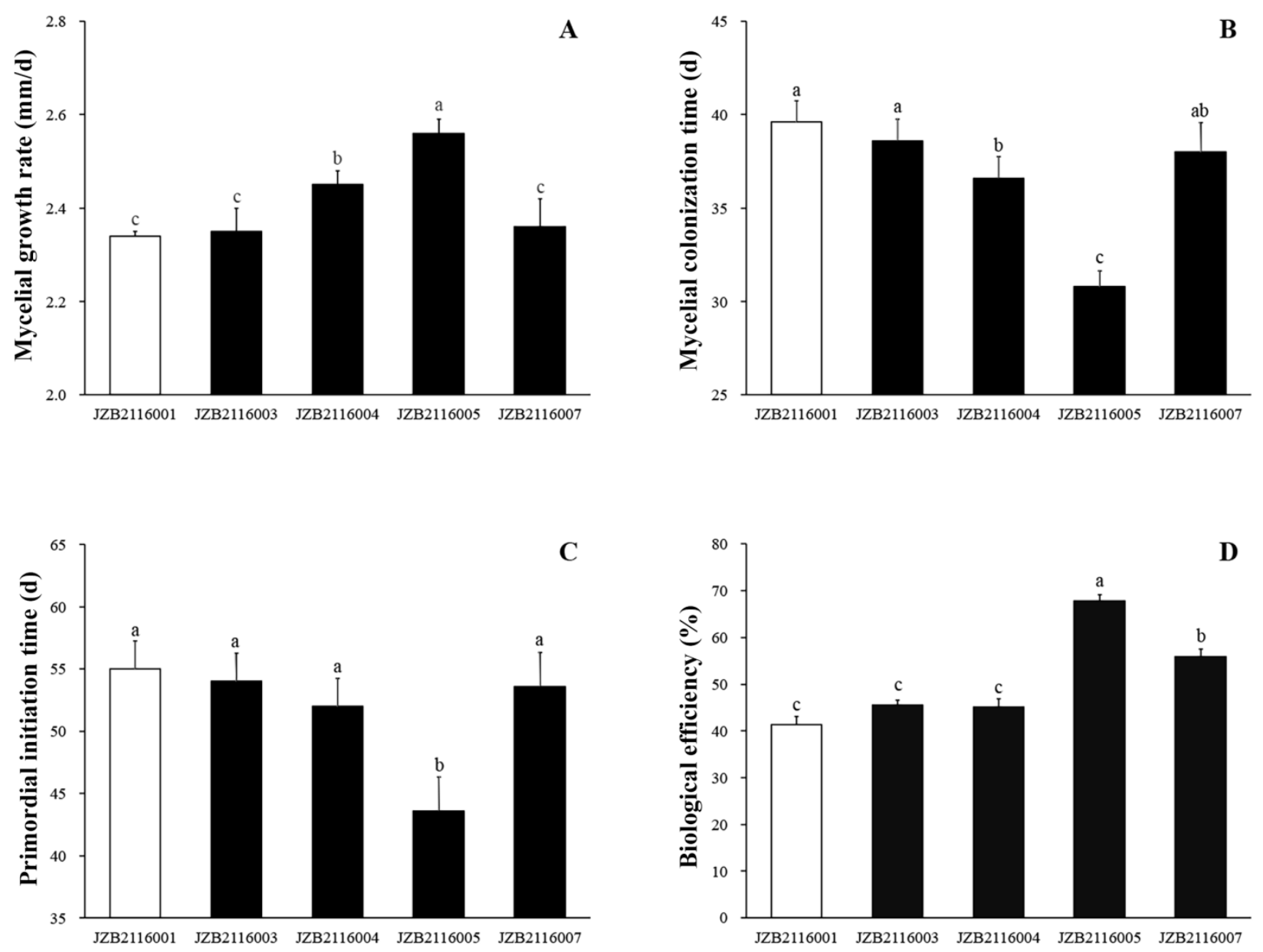

Fig. 1 - Comparison of the mycelial growth rate (MGR) (A), mycelial colonization time (MCT) (B), primordial initiation time (PIT) (C), and biological efficiency (BE) (D) of the tested Pholiota adiposa strains.

A, MGR was measured by the height $(\mathrm{mm})$ of the mycelia in the colonized substrates in racing tubes divided by the incubation time (days). B, MCT was measured by number of days from inoculation to complete colonization of the substrate by the mycelium in the culture bag. C, PIT was measured by number of days from inoculation to pinhead fruiting bodies. D, BE $(\%)=$ Weight of fresh mushrooms harvested per bag/weight of dry weight per bag $\times 100$.

Table 2 Comparison of the morphological traits of the tested Pholiota adiposa fruiting bodies ${ }^{\text {a }}$ $(\mathrm{mm})($ mean $\pm \mathrm{SD}, \mathrm{n}=20)$.

\begin{tabular}{ccccc}
\hline Strain No. & Stipe length & Stipe Diameter & Pileus thickness & Pileus diameter \\
\hline JZB2116001 & $94.83 \pm 4.83 \mathrm{a}$ & $9.67 \pm 1.03 \mathrm{~b}$ & $9.17 \pm 0.41 \mathrm{a}$ & $45.67 \pm 3.61 \mathrm{a}$ \\
JZB2116003 & $90.00 \pm 6.28 \mathrm{a}$ & $9.60 \pm 0.55 \mathrm{~b}$ & $7.40 \pm 1.34 \mathrm{~b}$ & $23.60 \pm 5.18 \mathrm{bc}$ \\
JZB2116004 & $72.40 \pm 7.13 \mathrm{~b}$ & $11.40 \pm 2.79 \mathrm{~b}$ & $6.00 \pm 0.71 \mathrm{c}$ & $18.40 \pm 2.07 \mathrm{c}$ \\
JZB2116005 & $95.80 \pm 8.67 \mathrm{a}$ & $11.00 \pm 1.58 \mathrm{~b}$ & $7.80 \pm 0.84 \mathrm{~b}$ & $25.40 \pm 5.41 \mathrm{~b}$ \\
JZB2116007 & $65.20 \pm 5.54 \mathrm{~b}$ & $16.00 \pm 1.87 \mathrm{a}$ & $8.20 \pm 2.05 \mathrm{ab}$ & $28.60 \pm 4.34 \mathrm{~b}$ \\
\hline
\end{tabular}

${ }^{a}$ Means in each column followed by the same superscripts are not significantly different at $P<0.05$ according to Duncan's multiple range tests. 
Table 3 Comparison of the chemical compositions of the tested Pholiota adiposa fruiting bodies ${ }^{\mathrm{a}}$ ( $\mathrm{g}$ in $100 \mathrm{~g}$ of dry matter, mean $\pm \mathrm{SD}, \mathrm{n}=3$ ).

\begin{tabular}{cccccc}
\hline Parameter & JZB2116001 & JZB2116003 & JZB2116004 & JZB2116005 & JZB2116007 \\
\hline Moisture $(\mathrm{g})$ & $6.82 \pm 0.05 \mathrm{a}$ & $6.82 \pm 0.04 \mathrm{a}$ & $6.78 \pm 0.03 \mathrm{a}$ & $6.80 \pm 0.06 \mathrm{a}$ & $6.78 \pm 0.09 \mathrm{a}$ \\
Ash $(\mathrm{g})$ & $6.12 \pm 0.03 \mathrm{c}$ & $6.20 \pm 0.12 \mathrm{c}$ & $7.44 \pm 0.19 \mathrm{a}$ & $7.36 \pm 0.15 \mathrm{a}$ & $6.60 \pm 0.12 \mathrm{~b}$ \\
Protein $(\mathrm{g})$ & $21.90 \pm 0.14 \mathrm{c}$ & $23.20 \pm 0.30 \mathrm{~b}$ & $27.20 \pm 0.11 \mathrm{a}$ & $26.60 \pm 0.80 \mathrm{a}$ & $23.20 \pm 0.42 \mathrm{~b}$ \\
Fat $(\mathrm{g})$ & $2.10 \pm 0.01 \mathrm{~b}$ & $1.70 \pm 0.05 \mathrm{~d}$ & $2.30 \pm 0.01 \mathrm{a}$ & $1.90 \pm 0.03 \mathrm{c}$ & $2.40 \pm 0.13 \mathrm{a}$ \\
Dietary fiber $(\mathrm{g})$ & $30.50 \pm 0.23 \mathrm{a}$ & $31.10 \pm 0.58 \mathrm{a}$ & $30.50 \pm 0.81 \mathrm{a}$ & $27.40 \pm 0.82 \mathrm{~b}$ & $27.70 \pm 0.78 \mathrm{~b}$ \\
Carbohydrate $(\mathrm{g})$ & $32.56 \pm 0.25 \mathrm{a}$ & $30.98 \pm 1.01 \mathrm{ab}$ & $25.78 \pm 1.13 \mathrm{c}$ & $29.94 \pm 1.84 \mathrm{~b}$ & $33.32 \pm 1.28 \mathrm{a}$ \\
Energy $(\mathrm{kcal})$ & $298.16 \pm 1.53 \mathrm{~b}$ & $294.64 \pm 1.92 \mathrm{c}$ & $293.92 \pm 2.02 \mathrm{c}$ & $298.92 \pm 5.05 \mathrm{~b}$ & $303.83 \pm 2.01 \mathrm{a}$ \\
\hline
\end{tabular}

${ }^{a}$ Means in each column followed by the same superscripts are not significantly different at $\mathrm{P}<0.05$ according to Duncan's multiple range tests.

Table 4 Comparison of the amino acid concentration and composition of tested Pholiota adiposa fruiting bodies $^{\mathrm{a}}$ ( $\mathrm{g}$ in $100 \mathrm{~g}$ of dry matter, mean $\pm \mathrm{SD}, \mathrm{n}=3$ ).

\begin{tabular}{cccccc}
\hline Amino acids & JZB2116001 & JZB2116003 & JZB2116004 & JZB2116005 & JZB2116007 \\
\hline Asparagine & $1.46 \pm 0.01 \mathrm{c}$ & $1.57 \pm 0.02 \mathrm{~b}$ & $1.87 \pm 0.02 \mathrm{a}$ & $1.24 \pm 0.05 \mathrm{~d}$ & $1.09 \pm 0.03 \mathrm{e}$ \\
Threonine & $0.75 \pm 0.01 \mathrm{c}$ & $0.79 \pm 0.03 \mathrm{~b}$ & $0.98 \pm 0.01 \mathrm{a}$ & $0.68 \pm 0.03 \mathrm{~d}$ & $0.59 \pm 0.02 \mathrm{e}$ \\
Serine & $0.78 \pm 0.01 \mathrm{c}$ & $0.87 \pm 0.04 \mathrm{~b}$ & $1.01 \pm 0.04 \mathrm{a}$ & $0.66 \pm 0.03 \mathrm{~d}$ & $0.58 \pm 0.01 \mathrm{e}$ \\
Glutamic acid $^{\mathrm{b}}$ & $3.21 \pm 0.05 \mathrm{~b}$ & $3.00 \pm 0.12 \mathrm{c}$ & $4.17 \pm 0.14 \mathrm{a}$ & $2.30 \pm 0.09 \mathrm{~d}$ & $2.31 \pm 0.01 \mathrm{~d}$ \\
Proline & $0.70 \pm 0.03 \mathrm{~b}$ & $0.72 \pm 0.01 \mathrm{~b}$ & $0.86 \pm 0.01 \mathrm{a}$ & $0.56 \pm 0.05 \mathrm{c}$ & $0.56 \pm 0.01 \mathrm{c}$ \\
Glycine & $0.66 \pm 0.01 \mathrm{c}$ & $0.72 \pm 0.01 \mathrm{~b}$ & $0.86 \pm 0.01 \mathrm{a}$ & $0.57 \pm 0.02 \mathrm{~d}$ & $0.51 \pm 0.02 \mathrm{e}$ \\
Alanine & $0.88 \pm 0.01 \mathrm{c}$ & $0.95 \pm 0.01 \mathrm{~b}$ & $1.13 \pm 0.01 \mathrm{a}$ & $0.78 \pm 0.03 \mathrm{~d}$ & $0.68 \pm 0.02 \mathrm{e}$ \\
Cystine & $0.13 \pm 0.01 \mathrm{c}$ & $0.18 \pm 0.00 \mathrm{~b}$ & $0.20 \pm 0.00 \mathrm{a}$ & $0.13 \pm 0.01 \mathrm{c}$ & $0.13 \pm 0.01 \mathrm{~d}$ \\
Valine $^{\mathrm{b}}$ & $0.71 \pm 0.00 \mathrm{c}$ & $0.77 \pm 0.01 \mathrm{~b}$ & $0.94 \pm 0.01 \mathrm{a}$ & $0.64 \pm 0.03 \mathrm{~d}$ & $0.56 \pm 0.02 \mathrm{e}$ \\
Methionine $^{\mathrm{b}}$ & $1.03 \pm 0.02 \mathrm{~cd}$ & $1.25 \pm 0.08 \mathrm{~b}$ & $2.60 \pm 0.16 \mathrm{a}$ & $1.04 \pm 0.05 \mathrm{~cd}$ & $1.16 \pm 0.04 \mathrm{bc}$ \\
Isoleucine $^{\mathrm{b}}$ & $0.73 \pm 0.01 \mathrm{c}$ & $0.83 \pm 0.01 \mathrm{~b}$ & $0.98 \pm 0.01 \mathrm{a}$ & $0.71 \pm 0.04 \mathrm{~cd}$ & $0.67 \pm 0.05 \mathrm{~d}$ \\
Leucine $^{\mathrm{b}}$ & $1.19 \pm 0.01 \mathrm{~cd}$ & $1.33 \pm 0.05 \mathrm{~b}$ & $1.55 \pm 0.02 \mathrm{a}$ & $1.12 \pm 0.06 \mathrm{~d}$ & $1.00 \pm 0.09 \mathrm{e}$ \\
Tyrosine $^{\mathrm{b}}$ & $0.40 \pm 0.00 \mathrm{c}$ & $0.47 \pm 0.01 \mathrm{~b}$ & $0.53 \pm 0.00 \mathrm{a}$ & $0.37 \pm 0.02 \mathrm{~d}$ & $0.33 \pm 0.02 \mathrm{e}$ \\
Phenylalanine $^{\mathrm{b}}$ & $0.80 \pm 0.01 \mathrm{c}$ & $0.90 \pm 0.03 \mathrm{~b}$ & $1.03 \pm 0.03 \mathrm{a}$ & $0.69 \pm 0.03 \mathrm{~d}$ & $0.62 \pm 0.03 \mathrm{e}$ \\
Lysine $^{\mathrm{b}}$ & $0.82 \pm 0.01 \mathrm{~d}$ & $0.97 \pm 0.01 \mathrm{~b}$ & $1.11 \pm 0.01 \mathrm{a}$ & $0.88 \pm 0.04 \mathrm{c}$ & $0.80 \pm 0.03 \mathrm{~d}$ \\
Histidine $_{\text {Tryptophan }}^{\mathrm{b}}$ & $0.33 \pm 0.00 \mathrm{c}$ & $0.38 \pm 0.01 \mathrm{~b}$ & $0.43 \pm 0.01 \mathrm{a}$ & $0.33 \pm 0.02 \mathrm{c}$ & $0.31 \pm 0.01 \mathrm{~d}$ \\
Arginine $^{\text {EAA }} \mathrm{c}$ & $0.20 \pm 0.00 \mathrm{e}$ & $0.28 \pm 0.00 \mathrm{~b}$ & $0.33 \pm 0.01 \mathrm{a}$ & $0.24 \pm 0.00 \mathrm{~cd}$ & $0.25 \pm 0.01 \mathrm{c}$ \\
NEAA $^{\mathrm{d}}$ & $1.10 \pm 0.02 \mathrm{c}$ & $1.19 \pm 0.02 \mathrm{~b}$ & $1.53 \pm 0.02 \mathrm{a}$ & $0.84 \pm 0.04 \mathrm{~d}$ & $0.81 \pm 0.04 \mathrm{~d}$ \\
TAA $^{\mathrm{e}}$ & $6.23 \pm 0.04 \mathrm{c}$ & $7.11 \pm 0.21 \mathrm{~b}$ & $9.52 \pm 0.26 \mathrm{a}$ & $5.99 \pm 0.28 \mathrm{~cd}$ & $5.62 \pm 0.27 \mathrm{~d}$ \\
EAA NEAA $^{\mathrm{f}}(\%)$ & $15.88 \pm 0.17 \mathrm{c}$ & $17.14 \pm 0.45 \mathrm{~b}$ & $22.11 \pm 0.51 \mathrm{a}$ & $13.78 \pm 0.62 \mathrm{~d}$ & $12.92 \pm 0.44 \mathrm{e}$ \\
EAA/TAA $^{\mathrm{g}}(\%)$ & $39.23 \pm 0.14 \mathrm{c}$ & $41.48 \pm 0.14 \mathrm{~b}$ & $43.06 \pm 0.16 \mathrm{a}$ & $43.46 \pm 0.04 \mathrm{a}$ & $43.50 \pm 0.63 \mathrm{a}$ \\
\hline
\end{tabular}

${ }^{a}$ Means in each column followed by the same superscripts are not significantly different at $\mathrm{P}<0.05$ according to Duncan's multiple range tests.

${ }^{\mathrm{b}}$ Essential amino acids.

${ }^{\mathrm{c}}$ EAA, total concentration of essential amino acids.

${ }^{\mathrm{d}}$ NEAA, total concentration of non-essential amino acids.

e TAA, total concentration of amino acids.

${ }^{\mathrm{f}}$ EAA/NEAA, total concentration of essential amino acids/total concentration of non-essential amino acids.

${ }^{\mathrm{g}}$ EAA/TAA, total concentration of essential amino acids/total concentration of amino acids. 
Table 5 Comparison of the chemical composition of different origins of the Pholiota spp. strains (g in $100 \mathrm{~g}$ of dry matter).

\begin{tabular}{|c|c|c|c|c|c|c|c|}
\hline Substrates & Protein & Fat & Ash & $\begin{array}{l}\text { Dietary } \\
\text { fiber }\end{array}$ & Carbohydrate & $\begin{array}{c}\text { Essential } \\
\text { amino } \\
\text { acids/Total } \\
\text { amino acids } \\
(\%) \\
\end{array}$ & $\begin{array}{l}\text { Essential amino } \\
\text { acids/ non- } \\
\text { Essential amino } \\
\text { acids }(\%)\end{array}$ \\
\hline Current study & $\begin{array}{l}21.90- \\
27.20\end{array}$ & $\begin{array}{l}1.70- \\
2.40\end{array}$ & $\begin{array}{c}6.12- \\
7.44\end{array}$ & $\begin{array}{l}27.40- \\
31.10\end{array}$ & $25.78-33.32$ & $39.23-43.60$ & $64.56-77.29$ \\
\hline $\begin{array}{l}\text { P. squarrosoides } \\
\text { (Wang et al. } \\
\text { 2014c) }\end{array}$ & 11.80 & 1.50 & 5.50 & 32.90 & 41.68 & 46.00 & 85.19 \\
\hline $\begin{array}{l}\text { P. adiposa (Hui et } \\
\text { al. 2003) }\end{array}$ & 21.64 & 1.22 & 5.88 & - & - & 37.87 & 60.95 \\
\hline $\begin{array}{c}\text { P. nameko (Xiang } \\
\text { et al. 2013) }\end{array}$ & 24.98 & 3.21 & 6.38 & - & - & $28.10^{*}$ & $39.08^{*}$ \\
\hline
\end{tabular}

* Tryptophan, one of the essential amino acids, was undetected.

\section{Production of P. adiposa}

$\mathrm{BE}$ and morphological traits of the tested $P$. adiposa fruiting bodies were presented in Figure $1 \mathrm{D}$ and Table 2, respectively. The highest $\mathrm{BE}$ of fruiting bodies $(67.88 \pm 1.33 \%)$ was for strain JZB2116005, followed by strain JZB216007, with a BE of $55.91 \pm 1.65 \%$; the control strain JZB2116001 showed the lowest BE of fruiting bodies $(41.35 \pm 1.72 \%)$. There was a significant difference between strain JZB2116005 and the others, and no difference was observed among strains JZB2116001, JZB2116003, and JZB2116004. Strain JZB2116005 displayed the longest stipe length $(95.80 \pm 8.67 \mathrm{~mm})$, but no significant difference was observed with strains JZB2116001 and JZB2116003; the values were $94.83 \pm 4.83 \mathrm{~mm}$ and $90.00 \pm 6.28 \mathrm{~mm}$, respectively. Strain JZB2116007 had the shortest stipe length $(65.20 \pm 5.54 \mathrm{~mm})$ and the largest stipe diameter $(16.00 \pm 1.87 \mathrm{~mm})$. The control strain JZB2116001 showed the largest value in the thickness and diameter of the pileus, with measurements of $9.17 \pm 0.41 \mathrm{~mm}$ and $45.67 \pm 3.61 \mathrm{~mm}$, respectively.

\section{Chemical contents of $P$. adiposa}

Table 3 indicates the chemical compositions of the $P$. adiposa fruiting bodies from different tested strains. Moisture contents of the $P$. adiposa samples were not significantly different among the tested strains. Ash content of the P. adiposa samples varied from 6.12 to $7.44 \mathrm{~g}$. The highest protein content was found in strain JZB2116004 $(27.20 \pm 0.11 \mathrm{~g})$, followed by strain JZB2116005 (26.60 $\pm 0.80 \mathrm{~g})$; the control strain JZB2116001 displayed the lowest protein content $(21.90 \pm 0.14 \mathrm{~g})$. Strains JZB2116004 and JZB2116005 showed no significant difference in protein content, but had a significant difference compared with the others. The fat content in strain JZB2116005 was $1.90 \pm 0.03 \mathrm{~g}$, which was higher than that of strain ZJB2116003 and lower than the other three tested strains. The highest amount of dietary fiber was found in strain JZB2116003 $(31.10 \pm 0.58 \mathrm{~g})$, followed by strains JZB2116001 and JZB2116004, which had an similar dietary fiber amount $(30.50 \pm 0.23 \mathrm{~g}, 30.50 \pm 0.81 \mathrm{~g})$; the lowest was in strain JZB2116005, with a dietary fiber amount of $27.40 \pm 0.82 \mathrm{~g}$. The carbohydrate content in strain JZB2116005 was $29.94 \pm 1.84 \mathrm{~g}$, which was higher than that of strain JZB2116004 (25.78 $\pm 1.13 \mathrm{~g})$ and lower than the others. The highest energy was recorded in strain JZB2116007 with $303.83 \pm 2.10 \mathrm{kcal}$, followed by strains JZB2116005 and JZB2116001, with energy values of $298.92 \pm 5.05$ and $298.16 \pm 1.53 \mathrm{kcal}$, respectively. Strain JZB2116004 demonstrated the lowest energy value ( $293.92 \pm 2.02 \mathrm{kcal})$.

Table 4 shows the concentrations of amino acids in different $P$. adiposa fruiting bodies. Interestingly, there was some regularity in the concentrations of the 18 amino acids in tested strains. The highest concentration of the 18 amino acids was in strain JZB2216004, followed by 
strain JZB2116003, except for glutamic acid, which showed a lower concentration $(3.00 \pm 0.12 \mathrm{~g})$ than that in control strain JZB2116001 $(3.21 \pm 0.05 \mathrm{~g})$. Total concentration of amino acids (TAA) in strain JZB2116005 was $13.78 \pm 0.62 \mathrm{~g}$, which was higher than that in strain JZB2116007 (12.92 $\pm 0.44 \mathrm{~g}$ ) and lower than the other three strains. Ratios of total concentration of essential amino acids (EAA)/total concentration of non-essential amino acids (NEAA) and EAA/TAA of the five tested strains were demonstrated in Table 4, the highest values were in strain JZB2116007 (77.01 \pm $1.96 \%$ and $43.50 \pm 0.63 \%$, respectively), followed by strain JZB2116005 $(76.86 \pm 0.13 \%$ and 43.46 $\pm 0.04 \%$, respectively) and JZB2116004 (75.64 $\pm 0.49 \%$ and $43.06 \pm 0.16 \%$, respectively). There were no significant differences among these three strains, and the lowest values were in control strain JZB2116001 (64.56 $\pm 0.37 \%$ and $39.23 \pm 0.14 \%$, respectively).

\section{Discussion}

In mushroom cultivation, the MGRs, PIT, yield, and BE are easily affected by the genotypes of the strains, the origins of the substrates, and the atmospheric conditions, which are typically different. In this study, the fruiting bodies of all the tested $P$. adiposa strains were successfully obtained on the substrates containing $60 \%$ cottonseed hull, $18 \%$ sawdust, $15 \%$ wheat bran, 5\% corn flour, 1\% gypsum, and 1\% lime. Strain JZB2116005 displayed the best characters compared with the others, especially with the control strain JZB2116001. The MGRs of the tested strains were correspond with the BE, but inconsistent with the MCT and PIT (Figure 1). The result of the present study was in agreement with that of Philippoussis (2001) and Baysal (2003) for the cultivation of $P$. ostreatus and Naraian (2009) for the cultivation of $P$. florida. Both of them reported rapid MGR, earlier PIT, and higher yield. However, in our previous comparision studies of tested strains with $P$. squarrosoide strain, $P$. squarrosoide demonstrated the significant difference in MGR, which was approximately $6 \mathrm{~d}$ earlier for colonizing the bags than P. adiposa JZB2116005, but it needed further 20-22 d for the after-ripening of the mycelia and the BE was $51.29 \%$ (Wang et al. 2014c), which was lower than that of $P$. adiposa strains JZB2116005 $(67.88 \pm 1.33 \%)$ and JZB2116007 (55.91 $\pm 1.65 \%$ ) (Figure 1 D) and displayed significant differences among each other (Data not shown). Therefore, strains with the highest MGR should represent a better physiological index that can colonize the whole substrates in a short time and avoid contamination, but the MGR should not be the only index to evaluate the quality of the strains in production. The BE of five tested $P$. adiposa strains was between 41.35 and $67.88 \%$ (Figure 1 D); strain JZB2116005 was 1.64-fold higher than the control strain JZB2116001, with a BE of $67.88 \pm 1.33 \%$ and $41.35 \pm$ $1.72 \%$, respectively. In addition, among the morphological traits of tested $P$. adiposa fruiting bodies, strain JZB2116005 demonstrated better morphological traits, with the longest stipe length and medium stipe diameter, pileus thickness, and pileus diameter, which were preferred by consumers, in comparison with the other tested strains.

Recently, many mushroom chemical analyses have been reported (Lee et al. 2011, Kulshreshtha et al. 2013, Wang et al. 2014c, Fernandes et al. 2015, Wang et al. 2015, Xu et al. 2015). However, the chemical composition is also easily affected by the strain genotype, substrate origin, and atmospheric conditions, which are usually different. In the present study, the chemical compositions and amino acids of the five tested $P$. adiposa strains were determined (Tables 3, 4), and comparisons of chemical their composition, EAA/TAA ratios and EAA/NEAA ratios of the five tested $P$. adiposa strains with the closely related species in literature are shown in Table 5. The protein contents varied from $21.90 \mathrm{~g}$ to $27.20 \mathrm{~g}$ and were higher than those of P. squarrosoide (11.80 g) (Wang et al. 2014c) and P. adiposa (21.64 g) (Hui et al. 2003). Of the five tested strains, the protein contents of strains JZB2116004 and JZB2116005 were $27.20 \pm 0.11 \mathrm{~g}$ and $26.60 \pm 0.80$ $\mathrm{g}$, respectively, which were higher than that of P. nameko (24.98 g) (Xiang \& Chen 2013). The fat contents (1.70-2.40 g) were higher than those of $P$. squarrosoide $(1.50 \mathrm{~g})$ (Wang et al. 2014c) and $P$. adiposa (1.22 g) (Hui et al. 2003) and lower than that of P. nameko (3.21 g) (Xiang \& Chen 2013). The ash contents varied from $6.12 \mathrm{~g}$ to $7.44 \mathrm{~g}$ and were higher than those of $P$. squarrosoide (5.50 g) (Wang et al. 2014c) and P. adiposa (5.88 g) (Hui et al. 2003). Of the five tested strains, the ash content of strains JZB2116004, JZB2116005, and JZB2116007 were $7.44 \pm 0.19 \mathrm{~g}, 7.36 \pm 0.15$ 
$\mathrm{g}$, and $6.60 \pm 0.12 \mathrm{~g}$, respectively, which were higher than that of $P$. nameko $(6.38 \mathrm{~g})$ (Xiang \& Chen 2013). The dietary fiber and carbohydrate contents of tested strains were 27.40-31.10 g and 25.78-33.32 g, respectively, which were all lower than those of P. squarrosoide with values 32.90 $\mathrm{g}$ and $41.68 \mathrm{~g}$, respectively (Wang et al. 2014c). The values of EAA/TAA and EAA/NEAA were 39.23-43.60\% and 64.56-77.29\%, respectively, which were all lower than those of P. squarrosoide (46.00\% and $85.19 \%$, respectively) (Wang et al. 2014c), whereas they were higher than those of $P$. adiposa (37.87\% and 60.95\%, respectively) (Hui et al. 2003) and P. nameko (28.10\% and 39.08\%, respectively) (Xiang \& Chen 2013). In addition, these values of the five tested strains were well above $40 \%$ EAA/TAA, and 60\% EAA/NEAA is considered to be adequate for an ideal protein food (FAO/WHO, 1973), except for the control strain JZB2116001, with 39.23\% EAA/TAA. Therefore, from chemical analyses, it could be concluded that fruiting bodies of strain JZB2116005 demonstrated better nutritional properties compared with the others. And it was necessary to optimize the cultivation formula or environmental factors of strain JZB2116005 for improving its chemical contents in the further research.

In conclusion, this is the first report of a comparative study on $P$. adiposa strains with different origins. From a commercial point of view, strain JZB2116005 has a clear advantage over the control strain JZB2116001 in terms of MGR, MCT, yield, BE, chemical compositions, and amino acid contents, and it is necessary to substitute strain JZB2116001 in production. Our findings will provide the foundation required for upgrading strains of other mushroom species in cultivation.

\section{Acknowledgements}

This work was financially supported by the Beijing Agriculture Innovation Consortium (BAIC05-2016), the Special Science and Technology Innovation Project of BAAFS (KJCX20151408) and the Major Program of Beijing Municipal Science \& Technology Commission (D151100004315003). We would like to thank to Prof. Xiaolan Mao (Institute of Microbiology, Chinese Academy of Sciences), for identification of the wild Pholiota strains and Dr. Jiye Yan (Institute of Plant and Environment Protection, Beijing Academy of Agriculture and Forestry Sciences), for providing valuable suggestions on the manuscript.

\section{References}

Baysal E, Peker H, Yalinkilic MK, Temiz A. 2003 - Cultivation of oyster mushroom on waste paper with some added supplementary materials. Bioresource Technology 89, 95-97.

Deng P, Zhang GQ, Zhou B, Lin RS, Jia L, Fan KM, Liu XN, Wang GY, Wang L, Zhang JJ. 2011 - Extraction and in vitro antioxidant activity of intracellular polysaccharide by Pholiota adiposa SX-02. Journal of Bioscience and Bioengineering 111, 50-54.

Deng YJ, Yang QY, Xie BG, Zhu J. 2014 - Variety test of 18 cultivated strains of Tremella fuciformis. Edible Fungi 4, 17-18.

Dulger B. 2004 - Antimicrobial activity of the macrofungus Pholiota adiposa. Fitoterapia 75, 395397.

FAO/WHO. 1973 - Joint FAO/WHO food standards programme codex committee nutrition and food hygiene.

Fernandes A, Barros L, Martins A, Herbert P, Ferreira ICFR. 2015 - Nutritional characterisation of Pleurotus ostreatus (Jacq. ex Fr.) P. Kumm. produced using paper scraps as substrate. Food Chemistry 169, 396-400.

Gregori A, Švagelj M, Pahor B, Berovič M, Pohleven F. 2008 - The use of spent brewery grains for Pleurotus ostreatus cultivation and enzyme production. New Biotechnology 25, 157-161.

Hu QX, Wang HX, Ng TB. 2012 - Isolation and purification of polysaccharides with anti-tumor activity from Pholiota adiposa (Batsch) P. Kumm. (higher Basidiomycetes). International Journal of Medicinal Mushrooms 14, 271-284.

Hui FL, Wei MH, Liu Z. 2003 - Analysis of Nutritional Components in the Fruitbodies of Pholiota adiposa. Acta Edulis Fungi 10, 20-23. 
Ji YM, Hu QX, Gong CT, Guo G. 2007 - Antioxidation study of extra-polysaccharides extracted from Pholiota adiposa (Fr.) Quel.. Biotechnology 17, 29-31.

Jiang X, Ding XM, Liu HY, Mi ZQ. 2007 - Effect of crude polysaccharides of Pholiota adiposa on antitumor and immunity in bearing-tumor mice. China Pharmacist 10, 119-121.

Ko HG, Park HG, Park SH, Choi CW, Kim SH, Park WM. 2005 - Comparative study of mycelial growth and basidiomata formation in seven different species of the edible mushroom genus Hericium. Bioresource Technology 96, 1439-1444.

Kulshreshtha S, Mathur N, Bhatnagar P, Kulshreshtha S. 2013 - Cultivation of Pleurotus citrinopileatus on handmade paper and cardboard industrial wastes. Industrial Crops and Products 41, 340-346.

Lee KJ, Yun IJ, Kim KH, Lim SH, Ham HJ, EumWS, Joo JH. 2011 - Amino acid and fatty acid compositions of Agrocybe chaxingu, an edible mushroom. Journal of Food Composition And Analysis 24, 175-178.

Li HM, Zheng BZ, Zhang MQ, Chu W. 2015 - Study on high yield cultivation techniques of Pholiota adiposa. China Fruit Vegetable 35, 64-66.

Li J, Qi Y. 2010 - Study on the domestication of wild Pholiota adiposa. Edible Fungi 4, 23-24.

Meng JL, Liang ZY, Liu JY, Chang MC. 2006 - Study on the cultivation mode of high yield and quality Pholiota adiposa. Edible Fungi of China 25, 27-30.

Morimoto N, Kinugawa K, Komatsu S. 1979 - Commercial cultivation of Pholiota adiposa on a sawdust ricebran substrate. Environment Control in Biology 17, 123-126.

Naraian R, Sahu RK, Kumar S, Garg SK, Singh CS, Kanaujia RS. 2009 - Influence of different nitrogen rich supplements during cultivation of Pleurotus florida on corn cob substrate. Environmentalist 29, 1-7.

Pant D, Reddy UG, Adholeya A. 2006 - Cultivation of oyster mushrooms on wheat straw and bagasse substrate amended with distillery effluent. World Journal of Microbiology and Biotechnology 22, 267-275.

Philippoussis A, Zervakis G, Diamantopoulou P. 2001 - Bioconversion of agricultural lignocellulosic wastes through the cultivation of the edible mushrooms Agrocybe aegerita, Volvariella volvacea and Pleurotus spp. World Journal of Microbiology and Biotechnology 17, 191-200.

Salmones D, Mata G, Waliszewski KN. 2005 - Comparative culturing of Pleurotus spp. on coffee pulp and wheat straw, biomass production and substrate biodegradation. Bioresource Technology 96, 537-544.

Shen L, Xing JX, Zeng QC, Wang JH. 2009 - Ecological environment of Pholiota adiposa (Wildtype) in Dezhou and the initial domestication and cultivation. Journal of Dezhou University $25,38-40$.

Shimizu K, Fujita R, Kondo R, Sakai K, Kaneko S. 2003 - Morphological features and dietary functional components in fruit bodies of two strains of Pholiota adiposa grown on artificial beds. Journal of Wood Science 49, 193-196.

Wang CR, Zhou R, Ng TB, Wong JH, Qiao WT, Liu F. 2014a - First report on isolation of methyl gallate with antioxidant, anti-HIV-1 and HIV-1 enzyme inhibitory activities from a mushroom (Pholiota adiposa). Environmental Toxicology and Pharmacology 37, 626-637.

Wang HX, Li AB, Wang DY, Wang HX. 2014b - Comparison test of four strains of Pleurotus ostreatus. Heilongjiang Agicultural Sciences 11, 130-131.

Wang SX, Xu F, Li ZM, Zhao S, Song S, Rong CB, Geng XL, Liu Y. 2015 - The spent mushroom substrates of Hypsizigus marmoreus can be an effective component for growing the oyster mushroom Pleurotus ostreatus. Scientia Horticulturae 186, 217-222.

Wang SX, Yang Q, Liu Y, Xu F, Sun MJ, Wang LQ, Zhao S. 2014c - Analysis of domestication, cultivation and nutritional components Pholiota squarrosoides (Peck) Sacc.. Journal of Northeast Agicultural University 45, 66-72.

Wang ZF, Wen SH. 2014 - Variety comparison experiment of Flammulina velutipes. Northern Horticulture 22, 150-151. 
Wu ZH, Peng XW, Zhou TB, Xie WQ, Han XQ. 2011 - Comparative study on the new strains of Pleurotus eryngii. Journal of Hebei Agicultural Sciences 15, 26-28.

Xiang Y, Chen J. 2013 - Analysis and Evaluation of Nutritional Components in Fruit Body of Pholiota nameko. Food Science 34, 238-242.

Xu F, Li ZM, Liu Y, Rong CB, Wang SX. 2015 - Evaluation of edible mushroom Oudemansiella canarii cultivation on different lignocellulosic substrates. Saudi Journal of Biological Sciences. In press, Corrected Proof, Available online.

Yang WJ, Guo FL, Wan ZJ. 2013 - Yield and size of oyster mushroom grown on rice/wheat straw basal substrate supplemented with cotton seed hull. Saudi Journal of Biological Sciences 20, 333-338.

Zhang GQ, Sun J, Wang HX, Ng TB. 2009 - A novel lectin with antiproliferative activity from the medicinal mushroom Pholiota adiposa. Acta Biochimica Polonica 56, 415-421.

Zhang LJ, Liu SX, Luo XK, Shang LE, Xu PX, Guo YH. 2015 - Variety test of 26 cultivated strains of Flammulina velutipes. Edible Fungi of China 34, 39-43.

Zhang YD, Xu K, Zhang DL, Fang FF. 2012 - The variety test of nine high temperature resistant strains of Pleurotus ostreatus. Northern Horticulture 12, 182-183. 